\title{
OPTIMALISASI BIAYA TRANSPORTASI PENDISTRIBUSIAN PRODUK PANGAN DI KOTA PALU MENGGUNAKAN MODEL TRANSPORTASI METODE MODIFIED DISTRIBUTION (MODI) (STUDI KASUS: PT. INDOMARCO ADI PRIMA)
}

\author{
D. Yuliandari' ${ }^{1}$ A. I. Jaya ${ }^{2}$, N. Nacong ${ }^{3}$ \\ 1,2,3Program Studi Matematika Jurusan Matematika FMIPA Universitas Tadulako \\ Jalan Soekarno-Hatta Km. 09 Tondo, Palu 94118, Indonesia. \\ 11@dessyyuliandari8@gmail.com, 2jayaindraagus@gmail.com,3nasrianacong@gmail.com
}

\begin{abstract}
Every company in the world always expects the maximum profit possible so that the company's life cycle runs well. For this reason, the company must be able to regulate the costs used so that there is a range between the company's expenses and income. PT. Indomarco Adi Prima is one of the companies engaged in food products, it is still difficult to determine the right method in optimizing transportation costs. Therefore, this study aims to obtain optimal transportation costs at PT. Indomarco Adi Prima in Palu city using the Modified Distribution (MODI) method. The results of this study indicate that before applying the Modified Distribution (MODI) method, the transportation costs incurred by PT. Indomarco Adi Prima, which is Rp. 61.510 .000 and transportation costs that are generated after using the Modified Distribution (MODI) method are Rp. 55.565.000. This shows that PT. Indomarco Adi Prima can optimize transportation costs for the distribution of food products in December 2020 with a distribution cost savings of Rp. $5,945,000$ or around $10.7 \%$.
\end{abstract}

Keywords : : Modified Distribution (MODI), Optimal Solutions, Transportation Costs

\section{ABSTRAK}

Setiap perusahaan di dunia selalu mengharapkan keuntungan yang semaksimal mungkin agar siklus hidup perusahaan tersebut berjalan dengan baik. Untuk itu, perusahaan tersebut harus mampu mengatur sedemikian rupa biaya yang digunakan agar tetap terjadi rentang antara pengeluaran dan pemasukan perusahaan. PT. Indomarco Adi Prima merupakan salah satu perusahaan yang bergerak dalam bidang produk pangan masih kesulitan untuk menentukan metode yang tepat dalam mengoptimalkan biaya transportasi. Oleh karena itu, penelitian ini bertujuan untuk memperoleh biaya transportasi optimal pada PT. Indomarco Adi Prima di kota Palu dengan menggunakan metode Modified Distribution (MODI). Dari hasil penelitian ini menunjukkan bahwa sebelum menerapkan metode Modified Distribution (MODI) biaya transportasi yang dikeluarkan oleh PT. Indomarco Adi Prima yaitu sebesar Rp. 61.510.000 dan biaya transportasi yang di hasilkan setelah menggunakan metode Modified Distribution (MODI) yaitu sebesar Rp. 55.565.000. Hal ini menunjukkan bahwa PT. Indomarco Adi Prima dapat mengoptimalkan biaya transportasi untuk pendistribusian produk pangan pada bulan Desember 2020 dengan penghematan biaya pendistribusian sebesar Rp. 5.945.000 atau sekitar 10,7\%.

Kata Kunci : Modified Distribution (MODI), Solusi Optimal, Biaya Transportasi 


\section{PENDAHULUAN}

\subsection{Latar Belakang}

Setiap perusahaan di dunia selalu mengharapkan keuntungan yang semaksimal mungkin agar siklus hidup perusahaan tersebut berjalan dengan baik. Untuk itu, perusahaan tersebut mampu mengatur sedemikian rupa biaya yang harus digunakan agar tetap terjadi rentang antara pengeluaran dan pemasukan perusahaan. Semakin besar rentang antara pemasukan dan pengeluaran perusahaan maka semakin besar pula keuntungan yang akan diperoleh dengan harapan pengeluaran selalu lebih rendah dari pada pemasukan perusahaan (Apriani, 2016).

Pada dasarnya, suatu perusahaan baik itu perusahaan yang bergerak dibidang industri jasa maupun manufacturing selalu berusaha menjamin kelancaran, kelangsungan hidup dan pertumbuhan baik jangka panjang maupun jangka pendek perusahaan tersebut, walaupun perusahaan mempunyai banyak tujuan yang harus dicapai, tetapi pada dasarnya tujuan utama perusahaan adalah mendapatkan keuntungan yang semaksimal mungkin (Ardhyani, 2017).

Perusahaan distribusi merupakan suatu perusahaan yang membeli barang dari produsen dan kemudian menjual kembali barang tersebut untuk memperoleh keuntungan. PT. Indomarco Adi Prima salah satu perusahaan yang tebentuk pada tahun 1951. Dimana, PT. Indomarco Adi Prima adalah unit bisnis dari PT. Indofood Sukses Makmur Tbk yang bergerak dibidang manufaktur pendistribusian consumer product. PT. Indomarco Adi Prima memiliki cabang diberbagai daerah yang berada di Indonesia salah satunya terletak di Kota Palu, Provinsi Sulawesi Tengah. Dalam hal meminimumkan biaya transportasi dalam pengalokasian produk bahan pangan kepada beberapa toko tujuan agen masih menjadi masalah bagi perusahaan. Oleh karena itu, PT. Indomarco Adi Prima membutuhkan metode yang tepat agar produk tersebut dapat didistribusikan dari beberapa agen (sumber) kebeberapa konsumen (pelanggan) sehingga menghasilkan biaya transportasi minimum.

Beberapa penelitian sebelumnya yang pernah dilakukan berhubungan dengan Metode Modified Distribution (MODI) antara lain Optimalisasi Pendistibusian Gas Elpiji $3 \mathrm{Kg}$ Di Kota Palu Dengan Menggunakan Metode Least Cost Dan Metode Modified Distribution (MODI) yang menghasilkan penghematan biaya transportasi pendistribusian yaitu sebesar $p .2 .509 .000$ atau sekitar 8,7\% (Labaso, 2015). Serta Penerapan Metode Modified Distribution (MODI) Dalam Meminimalisasi Biaya Transportasi Pengiriman Barang Di PT. Tirta Makmur Perkasa (Taufiq, 2017). Dimana hasil penelitian menghasilkan biaya minimum sebesar $R p$. 15.990 .365 atau sekitar 18\%. Sehingga peneliti tertarik untuk memecahkan masalahbiaya transportasi pendistribusian produk pangan pada PT. Indomarco Adi Prima di kota Palu menggunakan solusi awal metode Least Cost dan untuk mencari solusi optimal menggunakan metode 
Modified Distribution (MODI) yang bertujuan untuk mendapatkan biaya transportasi yang optimal.

\subsection{Batasan Masalah}

Adapun batasan masalah yang digunakan dalam penelitian ini adalah wilayah yang menjadi jangkauan pendistribusian produk pangan oleh PT. Indomarco Adi Prima adalah kota Palu. Data penelitian diambil pada tahun 2020.

\section{METODE PENELITIAN}

Pengambilan data penelitian ini bertempat di PT. Indomarco Adi Prima, data yang di ambil berupa data persediaan produk pangan, data permintaan pelanggan, data biaya transportasi setiap pengiriman produk pangan dari PT. Indomarco Adi Prma. Kemudian dilakukan pembuatan matriks transportasi lalu meerapkan Metode Least Cost untuk menentukan solusi awal dan selanjutnya menerapkan Metode Modified Distributon (MODI) untuk menentukan solusi optimal pada masalah transportasi pendistribusian produk pangan.

\section{HASIL DAN PEMBAHASAN}

\subsection{Hasil Penelitian}

Pendistribusian barang campuran oleh PT. Indomarco Adi Prima dilakukan melalui tiga agen. Adapun data persediaan barang campuran tersebut untuk masing-masing agen terlihat pada Tabel 1.

Tabel 1 : Data Persediaan Produk Pangan PT. Indomarco Adi Prima di tiga cabang pada bulan Desember 2020

\begin{tabular}{|c|c|c|c|}
\hline No & Nama Agen & Alamat & Persediaan (Karton) \\
\hline 1 & CV. Anugerah Jaya \\
Perkasa & Jl. Dr. Wahidin & 1750 \\
\hline 2 & PT. Tompotika Raya Palu & Jl. Towua & 1125 \\
\hline 3 & PT. Varia Kecana & J. RE Martadinata & 4610 \\
\hline
\end{tabular}

(Sumber : PT. Indomarco Adi Prima 2020)

Adapun data permintaan dari masing-masing toko pelanggan tersebut dapat dilihat pada Tabel 2. 
Tabel 2 : Permintaan Pelanggan Produk Pangan Pada Bulan Desember 2020

\begin{tabular}{|c|c|c|c|}
\hline No & Pelanggan & Alamat & $\begin{array}{c}\text { Permintaan } \\
\text { (Karton) }\end{array}$ \\
\hline 1 & Toko Aneka Makmur $\left(T_{1}\right)$ & $\begin{array}{l}\text { Jl.Tanjung } \\
\text { Manimbaya }\end{array}$ & 475 \\
\hline 2 & Toko Rahe $\left(T_{2}\right)$ & Jl.Cikditiro & 430 \\
\hline 3 & Toko Setia $\left(T_{3}\right)$ & Jl. Gajah Mada & 550 \\
\hline 4 & Toko Salex $\left(T_{4}\right)$ & Jl. Gatot Subroto & 465 \\
\hline 5 & $\begin{array}{l}\text { Toko Harmoni Indah Sentosa } \\
\qquad\left(T_{5}\right)\end{array}$ & Jl. Zebra & 470 \\
\hline 6 & Toko Jaya Abadi $\left(T_{6}\right)$ & JI. Imam Bonjol & 495 \\
\hline 7 & Toko Nusa Agung $\left(T_{7}\right)$ & Jl. Dr. Suharso & 430 \\
\hline 8 & Toko Baskara $\left(T_{8}\right)$ & Jl. Kemiri & 345 \\
\hline 9 & Toko Sinar Wajo $2\left(T_{9}\right)$ & Jl. Veteran & 410 \\
\hline 10 & Toko Abadi $\left(T_{10}\right)$ & $\begin{array}{c}\text { JI.Wolter } \\
\text { Munginsidi }\end{array}$ & 540 \\
\hline \multicolumn{3}{|c|}{ Jumlah } & 4610 \\
\hline
\end{tabular}

(Sumber : PT. Indomarco Adi Prima 2020)

Tabel 3 : Data Penawaran Produk Pangan Kesepuluh Toko Dari Masing-Masing Agen

\begin{tabular}{|c|r|c|c|c|c|}
\hline No & Toko & $\begin{array}{c}\text { CV. Anugerah Jaya } \\
\text { Perkasa } \\
\text { (Karton) }\left(\mathrm{S}_{1}\right)\end{array}$ & $\begin{array}{c}\text { PT. Tompotika } \\
\text { Raya Palu } \\
\text { (Karton)(S2) }\end{array}$ & $\begin{array}{c}\text { PT.Varia } \\
\text { Kencana } \\
\text { (Karton)(S3) }\end{array}$ & $\begin{array}{c}\text { Total } \\
\text { Permintaan }\end{array}$ \\
\hline 1 & $T_{1}$ & 180 & 190 & 105 & 475 \\
\hline 2 & $T_{2}$ & 165 & 170 & 95 & 430 \\
\hline 3 & $T_{3}$ & 210 & 190 & 150 & 550 \\
\hline 4 & $T_{4}$ & 185 & 185 & 95 & 465 \\
\hline 5 & $T_{5}$ & 190 & 180 & 100 & 470 \\
\hline 6 & $T_{6}$ & 155 & 255 & 85 & 495 \\
\hline 7 & $T_{7}$ & 170 & 140 & 120 & 430 \\
\hline 8 & $T_{8}$ & 145 & 100 & 100 & 345 \\
\hline 9 & $T_{9}$ & 170 & 110 & 130 & 410 \\
\hline 10 & $T_{10}$ & 180 & 215 & 145 & 540 \\
\hline
\end{tabular}

(Sumber : PT. Indomarco Adi Prima 2020) 
Berikut ini data biaya transportasi pendistribusian produk pangan untuk setiap unit dari agen menuju masing- masing pelanggan, yang dapat dilihat pada Tabel 4 .

Tabel 4 : Data biaya transportasi setiap pengiriman produk pangan dari agen menuju masingmasing pelanggan

\begin{tabular}{|c|c|c|c|c|c|c|c|c|c|c|}
\hline${ }_{\text {Dari }}^{\mathrm{Ke}}$ & $\begin{array}{c}\text { Toko } \\
1\end{array}$ & $\begin{array}{c}\text { Toko } \\
2\end{array}$ & $\begin{array}{c}\text { Toko } \\
3\end{array}$ & $\begin{array}{c}\text { Toko } \\
4\end{array}$ & $\begin{array}{c}\text { Toko } \\
5\end{array}$ & $\begin{array}{c}\text { Toko } \\
6\end{array}$ & $\begin{array}{c}\text { Toko } \\
7\end{array}$ & $\begin{array}{c}\text { Toko } \\
8\end{array}$ & $\begin{array}{c}\text { Toko } \\
9\end{array}$ & $\begin{array}{c}\text { Toko } \\
10\end{array}$ \\
\hline Agen & R & & $\mathrm{Rp}$ & $\mathrm{R}$ & $\mathrm{Rp}$ & $\mathrm{Rp}_{\mathrm{p}}$ & $\mathrm{Rp}$ & Rp & $\mathrm{Rp}_{\mathrm{p}}$ & Rp \\
\hline 1 & 3.000 & 11.000 & 12.000 & 11.000 & 15.000 & 12.000 & 11.000 & 14.000 & 14.000 & 13.000 \\
\hline Agen & Rp & $\mathrm{Rp}$ & $\mathrm{r}$ & $\mathrm{R}$ & $\mathrm{R}$ & $\mathrm{Rp}$ & $\mathrm{Rp}$ & $\mathrm{Rp}$ & $\mathrm{Rp}$ & $\mathrm{Rp}$ \\
\hline 2 & 12.000 & 13.000 & 14.000 & 14.000 & 11.000 & 15.000 & 14.000 & 15.000 & 15.000 & 11.000 \\
\hline Agen & $\mathrm{Rp}$ & p & Rp & $\mathrm{Rp}$ & $\mathrm{Rp}$ & $\mathrm{Rp}$ & Rp & $\mathrm{Rp}$ & $\mathrm{Rp}$ & $\mathrm{Rp}$ \\
\hline 3 & 16.000 & 14.000 & 15.000 & 14.000 & 17.000 & 15.000 & 14.000 & 16.000 & 11.000 & 15.000 \\
\hline
\end{tabular}

(Sumber : PT. Indomarco Adi Prima 2020)

Dari seluruh data yang diperoleh akan dibuat matriks model transportasi dapat dilihat pada Tabel 5.

Tabel 5 : Matriks Transportasi

\begin{tabular}{|c|c|c|c|c|c|c|c|c|c|c|c|}
\hline $\begin{array}{l}\text { Dari } \\
\mathrm{Ke}\end{array}$ & $T_{1}$ & $T_{2}$ & $T_{3}$ & $T_{4}$ & $T_{5}$ & $T_{6}$ & $T_{7}$ & $T_{8}$ & $T_{9}$ & $T_{10}$ & $\left(S_{i}\right)$ \\
\hline \multirow[t]{2}{*}{$S_{1}$} & 13 & 11 & 12 & 11 & 15 & 12 & 11 & 14 & 14 & 13 & 1750 \\
\hline & $X_{11}$ & $X_{12}$ & $X_{13}$ & $X_{14}$ & $X_{15}$ & $X_{16}$ & $X_{17}$ & $X_{18}$ & $X_{19}$ & $X_{1,10}$ & \\
\hline \multirow[t]{2}{*}{$S_{2}$} & 12 & 13 & 14 & 14 & 11 & 15 & 14 & 15 & 15 & 11 & 1735 \\
\hline & $X_{21}$ & $X_{22}$ & $\overline{X_{23}}$ & $X_{24}$ & $X_{25}$ & $X_{26}$ & $X_{27}$ & $X_{28}$ & $\overline{X_{29}}$ & $X_{2,10}$ & \\
\hline \multirow[t]{2}{*}{$S_{3}$} & 16 & 14 & 15 & 14 & 17 & 15 & 14 & 16 & 11 & 15 & 1125 \\
\hline & $X_{31}$ & $X_{32}$ & $\overline{X_{33}}$ & $X_{34}$ & $X_{35}$ & $X_{36}$ & $X_{37}$ & $X_{38}$ & $X_{39}$ & $X_{3,10}$ & \\
\hline$\left(P_{J}\right)$ & 475 & 430 & 550 & 465 & 470 & 495 & 430 & 345 & 410 & 540 & 4610 \\
\hline
\end{tabular}

Dari Tabel 5 model transportasi, akan diformulasikan model program linierna sebagai berikut :

Meminimumkan:

$$
\begin{aligned}
F & =13000 X_{11}+11000 X_{12}+12000 X_{13}+11000 X_{14}+15000 X_{15} \\
& +12000 X_{16}+11000 X_{17}+14000 X_{18}+14000 X_{19}+13000 X_{1,10} \\
& +12000 X_{21}+13000 X_{22}+14000 X_{23}+14000 X_{24}+11000 X_{25} \\
& +15000 X_{26}+14000 X_{27}+15000 X_{28}+15000 X_{29}+11000 X_{2,10} \\
& +16000 X_{31}+14000 X_{32}+15000 X_{33}+14000 X_{34}+17000 X_{35} \\
& +15000 X_{36}+14000 X_{37}+16000 X_{38}+11000 X_{39}+15000 X_{3,10}
\end{aligned}
$$


Dengan batasan:

$$
\begin{aligned}
& X_{11}+X_{12}+X_{13}+X_{14}+X_{15}+X_{16}+X_{17}+X_{18}+X_{19}+X_{1,10} \leq 1750 \\
& X_{21}+X_{22}+X_{23}+X_{24}+X_{25}+X_{26}+X_{27}+X_{28}+X_{29}+X_{2,10} \leq 1735 \\
& X_{31}+X_{32}+X_{33}+X_{34}+X_{35}+X_{36}+X_{37}+X_{38}+X_{39}+X_{3,10} \leq 1125 \\
& X_{11}+X_{21}+X_{31} \geq 475 \\
& X_{12}+X_{22}+X_{32} \geq 430 \\
& X_{13}+X_{23}+X_{33} \geq 550 \\
& X_{14}+X_{24}+X_{34} \geq 465 \\
& X_{15}+X_{25}+X_{35} \geq 470 \\
& X_{16}+X_{26}+X_{36} \geq 495 \\
& X_{17}+X_{27}+X_{37} \geq 430 \\
& X_{18}+X_{28}+X_{38} \geq 345 \\
& X_{19}+X_{29}+X_{39} \geq 410 \\
& X_{1,10}+X_{2,10}+X_{3,10} \geq 540
\end{aligned}
$$

\begin{tabular}{|c|c|c|c|c|c|c|c|c|c|c|c|}
\hline $\mathrm{Ke}$ & Toko & Toko & Toko & Toko & Toko & Toko & Tokc & Toko & Toko & Toko & $S_{i}$ \\
\hline Dari & 1 & 2 & 3 & 4 & 5 & 6 & 7 & 8 & 9 & 10 & \\
\hline$S_{1}$ & & 430 & 425 & 465 & & & 430 & & & & 1750 \\
\hline$S_{2}$ & 475 & & 125 & & 470 & 125 & & & & 540 & 1735 \\
\hline$S_{3}$ & & & & & & 370 & & 345 & 410 & & 1125 \\
\hline$P_{J}$ & 475 & 430 & 550 & 465 & 470 & 495 & 430 & 345 & 410 & 540 & 4610 \\
\hline
\end{tabular}

Selanjutnya dari data yang telah diperoleh akan dicari solusi awalnya dengan menggunakan metode Least Cost.

Tabel 6 : Tabel Solusi Awal Masalah Transportasi

Dari Tabel 6 dapat diketahui biaya transportasi pendistribusian produk pangan sebagai berikut:

$$
\begin{aligned}
& F=430\left(X_{12}\right)+425\left(X_{13}\right)+465\left(X_{14}\right)+430\left(X_{17}\right)+475\left(X_{21}\right) \\
&+ 125\left(X_{23}\right)+470\left(X_{25}\right)+125\left(X_{26}\right)+540\left(X_{2,10}\right) \\
&+ 370\left(X_{36}\right)+345\left(X_{38}\right)+410\left(X_{3,9}\right) \\
&=430(11000)+ 425(12000)+465(11000)+430(11000) \\
&+ 475(12000)+125(14000)+470(11000) \\
&+ 125(15000)+540(11000)+370(15000) \\
&+345(16000)+410(11000) \\
&=4.730 .000+5.100 .000+5.115 .000+4.730 .000+5.700 .000 \\
&+ \\
&+
\end{aligned}
$$


Hasil tersebut menggambarkan bahwa total biaya transportasi dari 3 agen pada PT. Indomarco Adi Prima menuju ke-10 toko dengan menggunakan metode Least Cost adalah sebesar Rp. 55.690 .000 perbulan. Untuk memperoleh biaya transportasi yang optimal pada pendistribusian produk pangan, langkah selanjutnya akan dikerjakan dengan menggunakan metode Modified Distribution (MODI).

Setelah dilakukan langkah-langkah dalam menentukan solusi optimal di dapatkan biaya transportasi optimal yang ditunjukkan pada Tabel 7.

Tabel 7 : Biaya Transportasi yang Optimal

\begin{tabular}{|c|c|c|c|c|c|c|c|c|c|c|c|c|}
\hline $\begin{array}{l}K_{j} \\
R_{i}\end{array}$ & & $\begin{array}{c}K_{1} \\
10\end{array}$ & $\begin{array}{l}K_{2} \\
11\end{array}$ & $\begin{array}{l}K_{3} \\
12\end{array}$ & $\begin{array}{c}K_{4} \\
11\end{array}$ & $\begin{array}{l}K 5 \\
9\end{array}$ & $\begin{array}{l}K_{6} \\
12\end{array}$ & $\begin{array}{l}K_{7} \\
11\end{array}$ & $\begin{array}{l}K_{8} \\
13\end{array}$ & $\begin{array}{l}K 9 \\
8\end{array}$ & $\begin{array}{c}K_{10} \\
9\end{array}$ & \multirow[t]{2}{*}{$\begin{array}{c}\text { Penaw } \\
\text { aran } \\
\left(S_{i}\right)\end{array}$} \\
\hline & $\begin{array}{l}\text { Dari } \\
\mathrm{Ke}\end{array}$ & $T_{1}$ & $T_{2}$ & $T_{3}$ & $T_{4}$ & $T_{5}$ & $T_{6}$ & $T_{7}$ & $T_{8}$ & $T 9$ & $T_{10}$ & \\
\hline $\begin{array}{l}R_{1} \\
0\end{array}$ & $S_{1}$ & 13 & $\underbrace{11}_{430}$ & $\underbrace{12}_{425}$ & $\underbrace{11}_{465}$ & 15 & 12 & ${ }_{430}^{11}$ & 14 & 14 & 13 & 1750 \\
\hline $\begin{array}{l}R 2 \\
2\end{array}$ & $S_{2}$ & $\underbrace{12}_{475}$ & 13 & $\begin{array}{r}14 \\
125\end{array}$ & 14 & $\underbrace{11}_{470}$ & 15 & 14 & $\underbrace{15}_{125}$ & 15 & $\underbrace{11}_{540}$ & 1735 \\
\hline $\begin{array}{r}R 3 \\
3\end{array}$ & $S_{3}$ & 16 & 14 & 15 & 14 & 17 & $\underbrace{15}_{495}$ & 14 & $\underbrace{16}_{220}$ & 410 & 15 & 1125 \\
\hline Perr & $\begin{array}{l}\text { intaan } \\
\text { J) }\end{array}$ & 475 & 430 & 550 & 465 & 470 & 495 & 430 & 345 & 410 & 540 & 4610 \\
\hline
\end{tabular}

$$
\begin{aligned}
\text { Biaya transportasi }= & 430(11000)+425(12000)+465(11000)+ \\
& 430(11000)+475(12000)+125(14000)+ \\
& 470(11000)+125(15000)+540(11000)+ \\
& 495(15000)+220(16000)+410(11000) \\
= & 4.730 .000+5.100 .000+5.115 .000+4.730 .000+5.700 .000 \\
& +1.750 .000+5.170 .000+1.875 .000+5.940 .000 \\
& +7.425 .000+3.520 .000+4.510 .000 \\
= & 55.565 .000
\end{aligned}
$$

\subsection{Pembahasan}

Pendistribusian produk pangan pada PT. Indomarco Adi Prima dilakukan melalui tiga agen dengan persediaan produk pangan ketiga agen yaitu Agen 1 sejumlah 1750 karton, Agen 2 sejumlah 1735, dan Agen 3 sejumlah 1125 karton. Masing-masing agen tersebut harus 
mendistribusikan hasil produknya kepada sepuluh toko yang merupakan pelanggan dari ke tiga agen. Jumlah permintaan dari masing-masing toko pelanggan produk pangan pada bulan Desember 2020 yaitu $T_{1}=475, T_{2}=430, T_{3}=550, T_{4}=465, T_{5}=470, T_{6}=495, T_{7}=430, T_{8}$ $=345, T_{9}=410, T_{10}=540$ dengan biaya transportasi yang berbeda-beda disesuaikan dengan jarak setiap kali pengiriman dengan total biaya transportasi untuk pendistribusian produk pangan dari ke tiga agen distributor menuju ke sepuluh toko pelanggan pada PT. Indomarco Adi Prima sebesar $R p .61 .510 .000$ pada bulan Desember 2020. Untuk mendapatkan biaya transportasi pendistribusian produk pangan yang optimal dilakukan perhitungan menggunakan model transportasi metode Modified Distribution (MODI), karena Indeks Perbaikan tidak ada bernilai negatif, tabel transportasi tidak memungkinkan untuk dimodifikasi lagi.

Tabel 7 merupakan tabel pemecahan optimal pendistribusian produk pangan ke sepuluh toko tujuan, yaitu: Toko Aneka Makmur ( $\left.T_{1}\right)$, Toko Rahe ( 2), Toko Setia ( $\left.T_{3}\right)$, Toko Salex ( $\left.T_{4}\right)$, Toko Harmoni Indah Sentosa ( $\left.T_{5}\right)$, Toko Jaya Abadi $\left(T_{6}\right)$, Toko Nusa Agung $\left(T_{7}\right)$, Toko Baskara( $T_{8}$ ), Toko Sinar Wajo 2 ( $\left.T_{9}\right)$, Toko Abadi ( $\left.T_{10}\right)$ dimana jumlah permintaan dan penawaran telah terpenuhi sebanyak 4610 karton. Agen 1 mendistribusikan produk pangan ke empat toko tujuan yaitu $\left(T_{2}, T_{3}, T_{4}\right.$, dan $\left.T_{7}\right)$, Agen 2 mendistribusikan produk pangan ke lima toko tujuan yaitu $\left(T_{1}, T_{3}, T_{5}, T_{8}\right.$, dan $\left.T_{10}\right)$, dan agen 3 mendistribusikan produk pangan ke tiga toko yaitu $\left(T_{6}, T_{8}\right.$, dan $\left.T_{9}\right)$, dengan total biaya transportasi $R p .55 .565 .000$ pada bulan Desember 2020.

Tabel 3 dapat disimpulkan bahwa terdapat perbedaan dalam mendistribusikan barang oleh agen. Distribusi sebelum menggunakan metode transportasi yang ditinjaukan Tabel 3 memperlihatkan tiga agen mendistribusikan produk pangan keseluruh toko tujuan dengan total biaya distribusi sebesar $R p .61 .510 .000$, sementara metode transportasi menghasilkan pola distribusi oleh setiap agen ke beberapa toko saja dengan biaya operasional mencapai $R p$. 55.565.000. Hal ini menunjukkan bahwa metode transportasi mampu memberikan solusi biaya yang minimum dalam upaya menekan biaya distribusi. Dimana pada kasus ini mampu menghemat biaya hingga $R p .5 .945 .000$.

\section{KESIMPULAN}

Berdasarkan hasil dan pembahasan, dapat disimpulkan bahwa biaya transportasi pendistribusian produk pangan pada PT. Indomarco Adi Prima pada bulan Desember 2020 dengan model Transportasi untuk solusi awal menggunakan Metode Least Cost yaitu sebesar $R p$. 55.690.000 dan untuk solusi optimal menggunakan Metode Modified Distribution (MODI) di peroleh biaya transportasi optimal yaitu sebesar $R p$. 55.565.000. Sedangkan biaya transportasi sebelum pengoptimalan dari perusahan yaitu sebesar $R p$. 61.510.000. Hal ini menunjukkan bahwa PT. Indomarco Adi Prima dapat mengoptimalkan biaya transportasi untuk pendistribusian Desember 2020 dengan penghematan biaya pendistribusian sebesar $R p .5 .945 .000$ atau sekitar $10,7 \%$. 


\section{DAFTAR PUSTAKA}

[1]. Aminudin., Prinsip-prinsip Riset Operasi, Erlangga, 2005, Jakarta.

[2]. Apriani T., Penerapan Model Transportasi Distribusi Pada Perusahaan Roti Dengan Menggunakan Metode Pendekatan Vogel, Metode Pendekatan Russel Dan Metode NWC (Sudut Barat Laut) Studi Kasus: PT. Gardenia, Universitas Negeri Alauddin, 2016, Makassar.

[3]. Ardhyani, I. W., Mengoptimalkan Biaya Distribusi Pakan Ternak Dengan Menggunakan Metode Transportasi (Studi Kasus Di PT, X Krian). Teknika: Engineering and Sains Journal, 2017, Vol. 1, No.2, Desember 2017, 95-100.

[4]. Claudia Nolman., Optimalisasi Pendistribusian AIR dengan menggunakan Metode Least Coast dan Metode Distribution, Jurnal IImiah Sains, 2013, Vol.13 No.1. Hal 5.

[5]. Dimyati, T. dan Dimyati, A, Operation Research Model-Model Pengambilan Keputusan, Sinar Baru Algesindo, 2004, Bandung.

[6]. Nurjuliawati Putri Haji, Aplikasi Stepping Tone untuk Optimasi Perencenaan Biaya Pada Suatu Proyek Kontruksi. Jurnal Sipil Statik, 2013, Vol 1 No.8. Hal 572.

[7]. Permata Sari, Desi., Optimasi Distribusi Gula Merah Pada UD sari Bumi Menggunakan Model Transportasi dan Model Least Cost. Sistem Informasi, 2010, Vol. 3 No.2.

[8]. Prawirosentono, S., Riset Operasi dan Ekonofisika, Bumi Askara, Jakarta. Siagian, Penelitian Operasional, 2006, (Jakarta: Penerbit Universitas Indonesia) H. 44-45.

[9]. Supranto, J., Linier Prograning, Fakultas Ekonomi, Universitas Indonesia, 1980, Jakarta.

[10]. Taha, H. A., Riset Operasi, Birorupa, Aksara, 1996, Jakarta Barat.

[11]. Taufiq, A, Penerapan Metode Modified Distribution (MODI) Dalam Meminimalisasi Biaya Transportasi Pengiriman Barang di PT. TIRTA MAKMUR PERKASA, Universitas Negeri Alauddin, 2017, Makassar. 